\title{
A Study of Serum Thyroid Stimulating Hormone and Prolactin Levels of Infertile Females
}

\author{
Dr .Omer Mohamed Shoaib ${ }^{1,}$ Dr. ELhashimi E. Hassan² \\ ${ }^{1,2}$ Department of Clinical Chemistry, Faculty of Medical Laboratory Sciences, Alzaeim Alazhari University -Sudan
}

\begin{abstract}
Background: Infertility represents a common condition nowadays, with important medical, economic and psychological implications. Traditionally, measurement of Prolactin (PRL) and thyroid hormones, especially thyroid stimulating hormone (TSH) has been considered an important component of infertility workup in females. Objective: The study was designed to evaluate the status of thyroid function in infertile Sudanese females and to investigate the impact of thyroid status on serum prolactin level. Method: In this retrospective case control study, we investigated seventy infertile females in the age range of 20-40 years attending department of Diagnostic and research unit at Khartoum teaching hospital for hormonal evaluation from March, 2014 to august, 2015. Thirty (30) healthy fertile females with similar age range were selected as controls group. The association between thyroid dysfunction and levels of serum Prolactin was reviewed. Results: In this study the results showed the means levels of TSH and T3 in study group were increased than control group but statistically not significant, $P$ value $>0.05$ and the mean of $T 4$ in the study group was significant increased than control group $<0.05$, while that the mean level of serum prolactin was significant decreased in the study group than control group. Majority of infertile females were euthyroid and there was no significant association between Infertility \& TSH (p > 0.05). Hyperprolactinemia was depicted in $24.3 \%$ infertile females. Prevalence of primary infertility was $76 \%$ while that of secondary infertility was $24 \%$ in study group, there was a significant positive correlation between serum TSH and Prolactin levels in infertile subjects with irregular menstrual cycle $(p<0.05)$. Conclusion: There was higher prevalence of hyperprolactinemia with normal thyroid function in infertile patients.
\end{abstract}

Keywords: Thyroid Stimulating Hormone, Hyperprolactinemia, Infertility.

\section{Introduction}

Infertility is generally defined as one year of unprotected intercourse without contraception. Approximately $85-90 \%$ of healthy young couples conceive within one year. Infertility affects $10-15 \%$ of couples [1].Hormonal disorders of female reproductive system are comprised of a number of problems resulting from aberrant dysfunction of hypothalamic- pituitary-ovarian axis. These relatively common disorders often lead to infertility. Thyroid dysfunction which is quite prevalent in the population affects many organs including male and female gonads, interferes with human reproductive physiology, which reduces the likelihood of pregnancy and adversely affects pregnancy outcome, thus becoming relevant in the algorithm of reproductive dysfunction.[2-3] Difficulty to conceive or subfertility constitutes a major psychological burden. Proper evaluation of these disorders involves multidimensional diagnostic approach, with a pivotal contribution from clinical laboratories [4]. Thyroid dysfunctions interfere with numerous aspects of reproduction and pregnancy. Therefore measurement of prolactin and thyroid hormones, especially thyroid stimulating hormone (TSH), has been considered an important component of infertility work up in women [5]. In the present study age matched (primary and secondary) infertile females were compared with normal fertile females to assess status of prolactin and thyroid stimulating hormone.

\section{Materials and Methods}

\subsection{Reagents}

All chemical reagents were purchased from Bio system company (Spine Company for Analytical material and chemical Reagents).

\subsection{Subjects and Study Population}

This was a hospital based, analytic, descriptive case control study, conducted in the Department of Diagnostic and Research Unit for hormones analysis and evaluation, at Khartoum teaching hospital, Sudan, from March 2014 to August 2015. The subjects were selected from the coming patients to (DRU) outpatients for hormonal studies. After informed consent, thyroid profile (TSH, thyroxin T4 and triiodothyronin T3) and serum PRL of all subjects was done at their first visit. 70 infetirile females (with both types of infertility) as study group and 30 healthy, fertile females in similar age range were enrolled as controls. The inclusion criteria for the selection of cases were diagnosis of infertility (both primary \& secondary) and age between 20-40 years. The exclusion criteria that were adopted during case selection were male factor infertility and amongst female factors were tubal factor, any congenital anomaly of urogenital tract or any obvious organic lesion. Any history of thyroid disease or previous thyroid surgery or being on medications for thyroid disorders or hyperprolactinemia was also amounted to exclusion for the study. These criteria were laid down after checking the detailed history of subjects recorded in a pre-designed data collection sheet in the Department of (DRU) at the time of sample collection. Samples were taken for evaluation of serum TSH, T4, T3 and PRL levels.

\subsection{Samples Collection and Preparation}

Five $\mathrm{ml}$ of blood samples were drawn from each individual of study population and controls group, using standard venipuncture techniques. Sample was allowed to clot for 30 minutes and then centrifuged at $3000 \mathrm{rpm}$ for 10 minutes to obtain clear, transparent serum. The separated serum was analysed for serum TSH, T4, T3 and PRL estimation or 


\section{International Journal of Science and Research (IJSR) \\ ISSN (Online): 2319-7064}

Index Copernicus Value (2013): 6.14 | Impact Factor (2015): 6.391

stored at 2-80c for maximum period of 5 days if not tested immediately. Serum T3, T4, TSH and PRL levels were estimated using immunoenzymatic method. Before processing the samples, each method was calibrated. The normal ranges for serum T3, T4, and TSH and are as follows: $0.51-1.58 \mathrm{ng} / \mathrm{ml}, 4.7-12.8 \mathrm{ug} / \mathrm{dl}, 0.28-6.28 \mu \mathrm{IU} / \mathrm{ml}$ and $1.2-19.0 \mathrm{ng} / \mathrm{ml}$ respectively. These values were used to confirm abnormal cases and then to find association between thyroid dysfunction and Prolactin levels. To calculate the prevalence of hyperthyroidism and hypothyroidism serum TSH level was considered. When serum TSH was $<0.39$ $\mu \mathrm{IU} / \mathrm{ml}$ hyperthyroidism was diagnosed. When serum TSH was $>3.5 \mathrm{uIU} / \mathrm{ml}$ hypothyroidism was diagnosed.

\subsection{Statistical Analysis}

For the statistical data analysis, descriptive statistics were used to show the characteristics of the infertile and fertile females (controls). Means were compared using independent ' $t$ ' test. Pearson/spearman correlation coefficient, whichever was applicable, has been used to see the correlation between infertility, PRL and TSH levels. A two-tailed, at minimum $95 \%$ confidence intervals \& p value $<0.05$ has been considered significant. All the data were analysed using Statistical package for social science (SPSS) version 20 (IBM, Chicago, USA).

\section{Result}

\section{Thyroid hormones}

The present study includes 70 subjects with infertility as case study and 30 ages matched and healthy, fertile females as control group. Most of the patients were in the age group of 20-40 years. As shown in [table1] serum T4 levels were found to be significantly increased in infertile females as compared to controls $(\mathrm{p}<0.05)$. And serum T3 levels was increased but not statistically significant $(\mathrm{p}>0.05)$ as shown in [Table1]. Moreover [Table 1] indicated that serum TSH levels were found to be increased but not statistically significant in infertile females as compared to controls $(p>0.05)$. However [Table 2] summarizes the percentage prevalence of thyroid status in infertile subjects

\section{Serum TSH}

The mean serum TSH levels in infertile female were $1.5 \pm 1.3 \mu \mathrm{IU} / \mathrm{ml}$ against the controls who had mean Serum TSH levels $1.2 \pm 0.7 \mu \mathrm{IU} / \mathrm{ml}$ (normal $=0.28-6.28 \mu \mathrm{IU} / \mathrm{ml})$ and both groups are not statistically significantly different to each other ( $p$ value $=0.200)$. [Table1]. Out of 70 infertile females, 2 (2.9\%) had higher TSH values than normal against controls.

\section{SerumT4}

The mean serum T4 levels is increased in infertile females $99.6 \pm 20.6 .3 \mu \mathrm{g} / \mathrm{l}$ against the fertile (controls) who had mean Serum T4 levels $80.2 \pm 19.2 \mu \mathrm{g} / 1$ (normal=4.7-12.8 ug/dl,) and there was statistically significant different between the two means ( $\mathrm{p}$ value $=0.000)$. [Table1]. Out of 70 infertile females, $6(8.6 \%)$ had higher T4 values than normal against controls.

\section{Serum T3}

The mean serum T3 levels in infertile patients were $1.5 \pm 0.4$ $\mathrm{ng} / \mathrm{ml}$ against the controls who had mean Serum T3 levels $1.3 \pm 0.2 \mathrm{ng} / \mathrm{ml}$ (euthyroid $=0.8-2 \mathrm{ng} / \mathrm{ml}$ ) and both groups are not statistically significantly different to each other ( $\mathrm{p}$ value $=0.510)$. [Table1]. Out of 70 infertile women, $2(2.9 \%)$ had higher T3 values than normal against controls, T3 values than normal.

\section{Serum PRL}

The mean prolactin levels in infertile patients were $17.7 \pm 25.8 \mathrm{ng} / \mathrm{ml}$ against the controls who had mean Prolactin levels of $20.9 \pm 26.3 \mathrm{ng} \mathrm{ng} / \mathrm{ml}$ (normal $=1.2-19$ $\mathrm{ng} / \mathrm{ml}$ ) and both groups are showing not statistically significant difference to each other $(\mathrm{p}$ value $=0.570)$ [Table $1]$.

Out of 70 infertile patients, $17(24.3 \%)$ had high prolactin levels (in both types of infertility) against control group.[Figure1] shows the percentage prevalence of hyperprolactinemia status in both types of infertility among test group. Hyperprolactinemia affects all age groups in our study; Hyperprolactinemia is more common seen in patients suffering from primary infertility which was found to be encountered 13 out of 17 patients $(76 \%)$ than those with secondary infertility (24\%).Hyperprolactinemia was depicted in $24.3 \%$ infertile females in our present study. Out of the 70infertile females, $76 \%$ were suffering from primary infertility while $24 \%$ were suffering from secondary infertility. There was a negative correlation between serum TSH and infertility.

Correlation between tow variables TSH and PRL levels:

The Pearson's correlation coefficient was calculated for serum TSH and PRL, serum TSH.Table [3] showed that prolactin level in patients group with irregular menstrual cycle is correlating positively and significantly with the TSH level, so by increasing TSH there is increase in the prolactin level.

Table 1: Mean \pm SD of hormone parameters in the infertile and control group

\begin{tabular}{|c|c|c|c|}
\hline Variable & $\begin{array}{c}\text { infertile } \\
\text { group }\end{array}$ & $\begin{array}{c}\text { Control } \\
\text { group }\end{array}$ & $\begin{array}{c}\text { P. } \\
\text { value }\end{array}$ \\
\hline TSH & $1.5 \pm 1.3$ & $1.2 \pm 0.7$ & 0.200 \\
\hline T4 & $99.6 \pm 20.6$ & $80.2 \pm 19.2$ & 0.000 \\
\hline T3 & $1.5 \pm 0.4$ & $1.3 \pm 0.2$ & 0.510 \\
\hline PRL & $17.7 \pm 25.8$ & $20.9 \pm 26.3$ & 0.570 \\
\hline
\end{tabular}

$P$. value $<0.05$ is statistically significant.

Table 2: Thyroid status in infertile females

\begin{tabular}{|c|c|c|c|c|}
\hline Age & No of & \multicolumn{3}{|c|}{ Thyroid status } \\
\cline { 3 - 5 } group & cases 70 & Hyperthyroidism & Hypothyroidism & Euthyroid \\
\hline $20-40$ & Percentage & $8(11 \%)$ & $2(3 \%)$ & $60(86 \%)$ \\
years & $(\%)$ & & & \\
\hline
\end{tabular}

Table 3: Correlation between TSH level and prolactin level in patients group

\begin{tabular}{|c|c|c|}
\hline \multirow{2}{*}{} & \multicolumn{2}{|c|}{ TSH } \\
\cline { 2 - 3 } & $\mathrm{r}$ & $\mathrm{p}$ \\
\hline PRL & 0.688 & 0.000 \\
\hline
\end{tabular}

$P$. value $<0.05$ is statistically significant. 


\section{International Journal of Science and Research (IJSR) \\ ISSN (Online): 2319-7064}

Index Copernicus Value (2013): 6.14 | Impact Factor (2015): 6.391

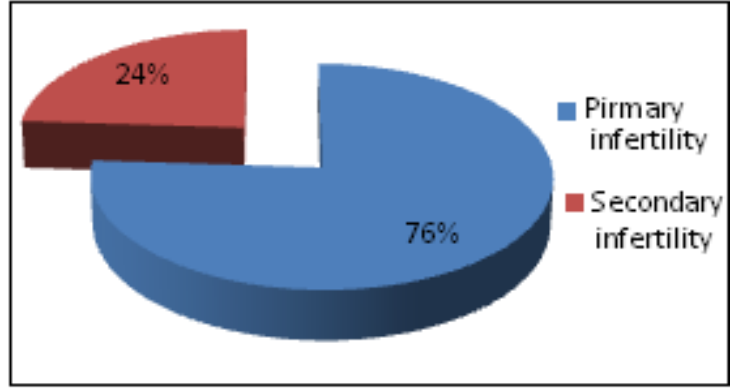

Figure 1: Shows the percentage prevalence of hyperprolactinemia status in both types of infertility

\section{Discussion}

Hypothyroidism is associated with increased production of TRH, which stimulates pituitary to secrete TSH and PRL. Hyperprolactinemia adversely affects fertility potential by impairing GnRH pulsatility and thereby ovarian function. Therefore in every infertile female should be investigated for TSH and PRL levels regardless of their menstrual rhythm at the time of initial consultation. In our study the age of infertile female is range from 20- 40 years, the prevalence of hypothyroidism in this age group was about 2-4\% [6] which is found to be $8 \%$ by Goswami et al [7] and $20 \%$ by Sharma et al [8], while in our present study this prevalence is $3 \%$ which is no similar to that of finding in above. In addition to thyroid profile other endocrine hormones like prolactin should be considered in infertility. Hyperprolactinemia and hypothyroidism are associated with infertility in females need more research and studies. Most of the study group were euthyroid the prevalence was found to be $60(86 \%)$, it is one of thyroid disturbances which effect regulatory of menstrual cycle and infertility statues. Thyroid dysfunction was reported to reduce the likelihood of conception and may affect pregnancy outcome [9].

Prevalence rate of women with both hypothyroidism and hyperprolactinemia increased throughout the screening period. Vidal et al [10] reported that higher prevalence of hypothyroidism and hyperprolactinemia in infertile women compared to fertile women, resulting in menstrual disorders which agreed with Goswami, et al, [7] who stated that hypothyroidism is commonly associated with hyperprolactinemia resulting in ovulatory failure, hence assessment of serum TSH and prolactin level are mandatory in the work of all infertile women specially with those with menstrual irregularities. Several mechanisms have been proposed for the increased serum prolactin level in primary hypothyroidism, of these mechanisms, attributed to increased prolactin secretion under the influence TRH which stimulates TSH as well PRL secretion[11 -12].Thyroid hormones themselves may play an important role in the cause of hyperprolactinemia, Davis et al [13] noticed that 3,5,3,- triodothyronine reduces prolactin messenger RNA levels in rodents hormones levels resulting in increased prolactin synthesis. Thyroid releasing hormone (TRH) is considered as a stimulant factor for rising prolactin level, estrogen may cause increase prolactin response to TRH that causes higher prolactin level in women [14]. Hyperprolactinemia is a common endocrine disorder of the hypothalamic-pituitary axis. It occurs more commonly in women. The prevalence of hyperprolactinemia ranges from
$0.4 \%$ in an unselected adult population to as high as $9-17 \%$ in women with reproductive diseases. Its prevalence was found to be $5 \%$ in a family planning clinic, $9 \%$ in women with adult onset amenorrhea, and $17 \%$ among women with polycystic ovary syndrome.[15] Our present study demonstrated that higher occurrence of hyperprolactinemia $(24.3 \%)$ was seen in infertile females. This higher propensity of hyperprolactinemia is in agreement with the findings of Kumkum et al who had depicted a prevalence of $46 \%$ in their study [16], It is found also in this study that the prevalence in agreement with the study done in Sudan by Hanadi et al who had found that the prevalence rate was $(20.6 \%)$ in their study which included 1685 infertile women with high TSH, 347 (20.6\%) were with high prolactin level [17]. Hyperprolactinemia affects all age groups in our study; Hyperprolactinemia is more common seen in patients suffering from primary infertility which was found to be encountered 13 out of 17 patients $(76 \%)$ than those with secondary infertility (24\%). The author demonstrated that there was a significant positive correlation, between TSH and PRL levels in patients group with irregular menstrual cycle, which was found also by Cramer and co-workers. Who states that TSH and prolactin were positively correlated in subclinical hypothyroid women [18]. This correlation was also documented in a study done in India in 2009 [19]. However, this cannot be observed regularly because some studies found that no correlation was observed between TSH and PRL levels, but they recommend further studies with a large sample size and long follow-up that are necessary to validate the variation in $\mathrm{TSH}$ and prolactin levels $[20,21]$.

\section{Conclusion}

In the present study there is moderate prevalence of hypothyroidism in infertile female. These disorders may lead to menstrual irregularities resulting in infertility. This is also associated with hyperprolactinemia and these patients are commonly associated with ovulatory failure. Hence, assessment of serum TSH and prolactin levels are mandatory in the work up of all infertile women, especially those presenting with menstrual irregularities. Since a significant correlation exists between serum TSH and prolactin levels in infertile females with irregular menstrual cycle, further studies with a large sample size and long follow-up that are necessary to validate the variation in TSH and prolactin levels.

\section{References}

[1] Mosher WD, Pratt WF. 1991 Fecundity And Infertility In The United States Journal Of Fertility And Sterility 56; 192.

[2] Poppe K, Velkeniers B: Thyroid and infertility. Verh K Acad Geneeskd Belg, 2002; 64(4):389-99.

[3] Poppe K, Glinoer D, Van S. A, Tournaye H, Devroey P, Schiettecatte $\mathbf{J}$ et al: Thyroid dysfunction and autoimmunity in infertile women. Thyroid, 2002:12(11):997-1001.

[4] Williams C, Giannopoulos T, Sherriff EA. Investigation of infertility with the emphasis on laboratory testing and with reference to radiological imaging. J Clin Pathol. 2003; 56:261-7. 


\section{International Journal of Science and Research (IJSR) \\ ISSN (Online): 2319-7064}

Index Copernicus Value (2013): 6.14 | Impact Factor (2015): 6.391

[5] Cramer DW, Sluss PM, Powers RD, McShane P, Ginsburgs ES, Hornstein MD, et al. Serum prolactin and $\mathrm{TSH}$ in an in vitro fertilization population: is there a link between fertilization and thyroid function? J Assist Reprod Genet. 2003; 20(6):210-5.

[6] Wang C, Crapo L M: The epidemiology of thyroid disease and implications for screening. Endocrinol Metab Clin North Am, 1997; 26(1):189-218.

[7] Goswami B, Patel S, Chatterjee M, Koner B C, SaxenaA.: Correlation of prolactin and thyroid hormone concentration with menstrual patterns in infertile women. J Reprod Infertil, 2009; 10(3):207-212.

[8] Sharma U R, Parmar C: Thyroid profile in infertile women and menstrual dysfunction. Source Indian Medical Gazette, updated 2007, www.endocrineindia.com/thyroidnewsite.

[9] Akhter, N and Hassan, M.A(2009) Subclinical hypothyroidism and hyperprolactinaemia in infertile women: Bangladesh perspective after universal salt iodinisation. The internet J Endocrinol 5(1):1-5

[10] Vidal E, Kovacs K, Cohen S,Lioyd R. and Scheithauer B.(2000) Transdifferentiation of somatotrophs to thyrotrophs in the pituitary in patients with protracted primary hypothyroidism. J. Virchows Arch. 436:43-51.

[11] Ezzat S, Asa SL, Couldwell WT, Bare CE, Vance ML, and Mc Cutcheon. (2004). The prevalence of pituitary adenomas: a systematic review. Cancer.101:613-619.

[12] Kroese JM, Grootendorst AF, and Schelfhout LJ.(2004). Postpartum amenorrhoea- galactorrhoea associated with hyperprolactinemia and pituitary enlargement in primary hypothyroidism. Net J Med. 62(1): 28-30.

[13] Davis JR, Lynam TC, Franklyn JA, Docherty K. and Sheppard MC. (1986). Tri-iodothyronine and phenythion reduce prolactin messenger RNA levels in cultured rat pituitary. J Endocrinol .109: 359-364.

[14] Adele B, Ozra A, Zahra K. andZakiie V. (2011) Hyperprolactinemiain association with subclinicalhypothyroidism. Caspian J Intern Med . 2 (2):229-233.

[15]Biller BM, Luciano A, Crosignani PG, Molitch M, Olive D, Rebar R, et al. Guidelines for the diagnosis and treatment of hyperprolactinemia. J Reprod Med. 1999;44(Suppl 12):1075-84.

[16] Kumkum A, Jasmine K, Shweta G, PalAjeshwar N. Hyperprolactinemia andits correlation with hypothyroidism ininfertile women. J Obstet Gynecol India.2006; 56(1): 68-71.

[17] Hanadi E, Abdelsalam A.M .College of Medical Laboratory Science, Omdurman Islamic University, Reproductive Health Care Center, Khartoum Journal of Natural and Medical Sciences (JNMS) vol. 15 (2) 2014 ISSN 1858-6805.

[18] Cramer DW, Sluss PM, Powers RD, McShane P, Ginsburgs ES, and Hornstein MD: Serum prolactin and TSH in an in vitro fertilization population: is there a link between fertilization and thyroid function? J Assist Reprod Genet. 2003: 20:210-5.

[19] Binita G, Suprava P, Mainak C, Koner BC, andAlpana S: Correlation of Prolactin and Thyroid Hormone Concentration with Menstrual Patterns in Infertile Women .2009: Vol 10, Issue 3 , no.40.

[20] Nasima A and Sufi A H: Sub-clinical hypothyroidism and hyperprolactinemia in infertile women: Bangladesh perspective after universal salt iodination. The Internet Journal of Endocrinology. 200Volum5 Number 1.

[21] Bals-Pratsch M , Schober O , and Hanker JP: Schilddru"sen-funktionssto"rungen und Sterilita"t der Frau. Zentrabl. Gyna"kol. 1993: 115, 24-26. 